\title{
Metodologia para articular processos de formação-intervenção -avaliação na educação profissional em enfermagem
}

\author{
Methodology to articulate the process of training-intervention-e- \\ valuation in the professional education in nursing
}

Serafim Barbosa Santos Filho (https://orcid.org/0000-0001-8397-6575) ${ }^{1}$

Kleyde Ventura de Souza (https://orcid.org/0000-0002-0971-1701) ${ }^{1}$

${ }^{1}$ Departamento de Enfermagem Materno Infantil e Saúde Pública, Núcleo de Pesquisas e Estudos em Saúde da Mulher e Gênero, Escola de Enfermagem, Universidade Federal de Minas Gerais. Av. Prof. Alfredo Balena 190, sala 438, Santa Efigênia. 30130-100 Belo Horizonte MG Brasil. serafimsantosfilho@ gmail.com

\begin{abstract}
This article presents a methodology for professional training in obstetrics nursing (ON) that goes beyond teaching specific competencies and contributes to the change in the model of childbirth care as proposed by Brazilian Unified Health System. This methodology addresses gaps and challenges in the current ON model and it builds on existing initiatives for the inclusion of $O N$ in the teamwork environment. The training-intervention-evaluation method proposes the inclusion of evaluation as part of the training, which is in line with methods for intervention research. A triangulation of strategies, techniques, and instruments is conducted articulated to analytical dimensions of obstetric and neonatal care. This methodology was implemented in multicentric ON courses coordinated by the Federal University of Minas Gerais (UFMG) between 2016 and 2018. A total of 20 ON courses across states, 1,150 professionals (students, faculty, coordinators, preceptors, and supervisors), and 400 health services (internship fields and teaching hospitals) participated in the process. In conclusion, based on the experiences of those participating in this project, the implementation of this methodology produced nurses more qualified and better prepared for practice and for adapting the model of childbirth care.
\end{abstract}

Key words Professional Training, Health Education, Nursing, Health work
Resumo O artigo apresenta uma metodologia de formação profissional em enfermagem obstétrica $(E O)$ na perspectiva de avançar para além da apropriação de competências específicas e contribuir com a mudança de modelo de atenção ao parto e nascimento, conforme proposto pelo Sistema Único de Saúde. Estudo que parte das lacunas do modelo atual e de cursos recentes para incentivo à inserção da EO na ótica do trabalho em equipe. Nesse contexto apresenta um caminho metodológico de formação-intervenção-avaliação, com eixos diretivos de uma prática avaliativa indissociada da formação, alinhando conceitos que sustentam a proposta nos moldes de pesquisa-intervenção. Nesse caminho triangulam-se estratégias, técnicas e instrumentos, articulados a dimensões de análise do trabalho na atenção obstetriconeonatal. A metodologia foi desenvolvida tendo por campo cursos multicêntricos de EO coordenados pela UFMG entre 2016 e 2018, abrangendo: 20 cursos descentralizados nos estados, 1.150 profissionais (alunos e agentes envolvidos na condução), 400 serviços (campos de práticas). Conclui-se a apresentação metodológica com os principais rumos de efeitos das experiências, afirmando-se a produção e qualificação de redes de enfermeiros para a assistência e interferência no modelo de cuidado ao parto e nascimento.

Palavras-chave Capacitação profissional, Educação em saúde, Enfermagem, Trabalho em saúde 


\section{Perspectiva da formação-intervenção: foco na enfermagem obstétrica}

A partir de 2011 o Ministério da Saúde (MS), por meio da Rede Cegonha, ampliou iniciativas de cursos estratégicos na Política de Saúde da Mulher, incluindo os de enfermagem obstétrica (EO), fomentando a formação de profissionais para contribuir com a mudança de modelo de atenção ao parto e nascimento ${ }^{1-3}$. Na parceria com o MS a Enfermagem da UFMG (EEUFMG) vem conduzindo uma série de cursos desde 2012 e, recentemente, alinhou estratégias pedagógicas no referencial da formação-intervenção, no compromisso de ampliar metodologias no rumo dos desafios apontados pelo MS. Assim estruturaram-se os cursos de especialização e aprimoramento que a EEUFMG vem coordenando desde 2016, em caráter multicêntrico, com 20 universidades colaboradoras, mais de 400 hospitais-maternidades, incluindo os de ensino, ampliando a formação para enfermeiros de todo o país.

Os objetivos centrais dos cursos foram atualizados para: contribuir para um novo modelo de atenção ao parto e nascimento, buscando melhoria dos indicadores de saúde materna e neonatal; fortalecer a Rede Cegonha e maternidades na transformação de seus modelos de cuidado e; nessas direções, formar enfermeiras para a assistência obstetriconeonatal, com foco no trabalho em equipe e capazes de contribuir com a reorganização dos serviços.

Ao convergir esses objetivos na formação-intervenção, busca-se ampliar a qualificação para interferência na organização e gestão dos processos de trabalho, superando abordagens educativas centradas na transmissão de conhecimentos e descoladas dos saberes da experiência. Esse desafio alinha-se a um dos princípios do Sistema Único de Saúde (SUS) - de integração ensino-serviço -, sendo o legítimo ordenador da formação profissional. Vale lembrar o cenário atual da atenção ao parto-nascimento no Brasil, com preocupantes indicadores de morbimortalidade, de cesarianas, vigência de práticas assistenciais inadequadas ${ }^{4} \mathrm{e}$ permanecendo dificuldades de inserção da EO na atuação interprofissional ${ }^{5,6}$.

O modelo obstetriconeonatal é ainda médico-hospitalocêntrico, nele cruzando-se uma complexa teia de saberes, interesses e poderes influindo nas práticas institucionais. A abertura educacional para este debate parte do princípio de que não bastam cursos para resolver a insuficiência e despreparo técnico de profissionais, mas formar para interferir na (baixa) capacidade de análise-intervenção no trabalho, no horizonte de atuação multiprofissional, na organização e gestão dos processos e das práticas. A finalidade principal da formação-intervenção é ampliar a rede de sujeitos aptos para intervir nos modos de gerir e de cuidar. Propõe, assim, interferência no trabalho, nele e com ele articulando produção de conhecimento, práticas de atenção e de gestão, produção de saúde e de sujeitos de modo indissociável. Em sua compreensão, formar equivale a intervir na situação, sempre coletiva, do trabalho ${ }^{7,8}$. No caminho metodológico desses processos formativos a avaliação assume função estratégica, articulando-se na tríade formação-intervenção-avaliação $0^{9}$ e o objetivo deste artigo é apresentar a articulação metodológica entre esses campos, trazendo eixos diretivos da prática avaliativa indissociada da formação, dialogando com os desafios do trabalho na atenção ao parto e nascimento.

\section{Articulando os campos da formação, trabalho e avaliação na perspectiva da formação-intervenção}

$\mathrm{Na}$ articulação entre formação, trabalho e avaliação esses referenciais cruzam-se no direcionamento dos processos de formação-intervenção e seus eixos político-pedagógicos ${ }^{9,10}$. Para isso, toma-se o conceito de transversalidade ${ }^{11}$ subsidiando as conexões desejadas entre tais campos de saberes e práticas. Nos tópicos seguintes demarcam-se os referenciais de formação e trabalho e em seguida avança-se nas bases avaliativas, considerando sua inserção estratégica no acompanhamento de todo o processo formativo. Assim a avaliação é pressuposta, e desdobrada, no rumo de pesquisa-intervenção ${ }^{12,13}$ e fazendo-se com o aporte de elementos da análise institucional e saberes afins ${ }^{12,14-18}$, agregando valor ao processo avaliativo.

\section{Formação-intervenção na perspectiva da transversalidade}

A perspectiva freireana sempre estará presente nos referenciais que valorizam a educação em sua dimensão política e concebendo a prática pedagógica associada à transformação da realidade. Nessa mesma direção a Política Nacional de Humanização (PNH) agregou uma concepção de formação-intervenção em seu marco teórico -político, pondo-a nos desafios de qualificação do SUS ${ }^{10,19}$. Essa pauta abre espaço para a discussão sobre a conhecida e nociva distância entre ensino-serviço, somando-se estratégias para sua 
superação. $\mathrm{Na}$ atenção ao parto e nascimento as lacunas se observam na ênfase dada ao preparo técnico de enfermeiros, pouco se atendo ao referencial do trabalho em equipe e para interferir nos processos de trabalho/gestão que continuam excluindo ou limitando sua inserção na prática. É nesse cenário que a formação-intervenção ganha sentido.

Aposta-se em uma formação que não feche os olhos ao complexo contexto de organização do trabalho e do cuidado no concreto dos serviços, que não se reduza a uma preparação tecnicista, que não negligencie as relações institucionais ou que não distancie atenção e gestão. Aposta em uma formação que problematize novos modos de cuidado e de gestão do trabalho, pondo em análise os modos tradicionais de trabalhar e de gerir e discutindo aspectos envolvidos na segmentação da prática. A tradição de modelos centralizadores e verticalizados de gestão e de formação reproduz-se em más práticas de cuidado. Daí que a mudança passa por movimentos para alterar, simultaneamente, as práticas de atenção, gestão e formação, vistas como indissociáveis. Assim afirma-se que a formação não se restringe à aquisição de conhecimento e competências de forma abstrata, mas que se desenvolve com base na realidade e vivências de trabalho, exigindo ampliação de marcos teórico-metodológicos para sua reflexão.

Ao se assumir como inseparáveis os modos de cuidar, de gerir e de formar, o conceito de transversalidade ${ }^{11}$ é então evocado como caminho para essas conexões, instigando-se a ruptura de fronteiras e de especialismos que segregam e fragmentam, da concentração e verticalização de saberes e poderes, e sustentando a ativação de forças instituintes para a construção de pontes entre áreas, saberes, práticas, serviços e sujeitos/ equipes na lógica do trabalho transdisciplinar e multiprofissional $^{20}$. Dessa concepção faz derivar novos desenhos de projetos formativos e de integração ensino-serviço, criando-se condições para aumentar o grau de participação e protagonismo nos espaços em que circulam (da formação e do trabalho).

Operar com a transversalidade na qualificação do enfermeiro para inserção na atenção ao parto é trazer para a cena formativa os elementos que se cruzam na arena do trabalho, abrindo discussões que passam pelo preparo técnico, mas também pelas tradicionais relações de saberes e poderes que interferem na (não) aceitação-inclusão efetiva desse profissional na ótica do trabalho em equipe e, por outro lado, pela análise das ma- croforças que convergem para manutenção do modelo hegemônico de atenção e de gestão.

\section{Trabalho e poder de agir dos sujeitos}

A concepção de trabalho na relação entre $o$ prescrito e o real está presente em vários autores ${ }^{21-25}$, tendo em comum a compreensão de que o trabalho opera-se a partir de normas antecedentes, que definem e orientam o que e como deve ser feito (âmbito do prescrito), mas em permanente processo de reinvenção dessas normas e regras, mecanismo que reflete o que os sujeitos imprimem no seu fazer cotidiano, incorporando a sua experiência e subjetividade no processo produtivo. $\mathrm{O}$ trabalho significa produção de saber e de conhecimento prático, campo de formação permanente, onde os sujeitos tornam-se competentes com o enfrentamento das demandas e situações vividas, criando estratégias para isso. A compreensão de competência comparece na relação direta com a prática de fazer-aprender ${ }^{21}$, não no sentido restrito de valores ou habilidades da prescrição profissional, mas como atitudes, posicionamentos, ações e aprendizados constituídos no confronto dos sujeitos com as situações que vivenciam.

O trabalho em saúde é um espaço onde se efetivam essas conexões e encontros entre os sujeitos da produção: trabalhadores entre si e com gestores e usuários. Pensar esse trabalho é então afirmar a transversalidade como alargamento comunicacional entre os sujeitos. Essa concepção remete ao desafio de uma participação ativa e inventiva de atores, saberes e serviços, em compartilhamento, voltados para o enfrentamento de problemas que emergem nos cotidianos de trabalho. Diz de uma aprendizagem, individual e coletiva, que se faz com as situações vividas, desenvolvendo a competência ${ }^{23}$ com os processos concretos de trabalho. Trata-se de um contexto considerado como produtor de potência, isto é, que na medida em que se aumenta o grau de transversalidade aumenta-se o poder de agir dos coletivos de trabalhadores ${ }^{15,25}$.

Destacar essa acepção de trabalho na formação do enfermeiro é trazer para a cena formativa a análise dos modos de trabalhar. O trabalho que se realiza ao cuidar do outro (mulher-criança) e ao se relacionar com os pares/colegas (âmbito dos processos de trabalho, gestão e aprendizagem permanente) não é guiado apenas pela racionalidade tecnocientífica, pelas prescrições e protocolos, nem obediência restrita a regras e normas. É atividade envolvendo tudo isso, mas 
fazendo-se num ato de (re)criação e de singularidade, onde cada sujeito se coloca a partir de seus saberes, sua história, sua cultura e seus valores. É por essa compreensão que se abre a perspectiva de analisar os hábitos, as escolhas, as adesões aos diferentes tipos de práticas, as resistências, os boicotes explícitos e implícitos e também os deslocamentos que os sujeitos fazem modificando suas próprias subjetividades a partir dos novos sentidos que se vão construindo acerca do parto e nascimento.Vale salientar que, como o trabalho na saúde em geral, a prática obstetriconeonatal acontece em meio às chamadas modernizações no sistema produtivo, crescendo em incorporação tecnológica, farmacomedicalização e padronizações, enrijecendo a relação assistencial e com perda de autonomia dos usuários e dos próprios profissionais em sua atividade ${ }^{26}$.

Por outro lado, na tradição da divisão técnica e social do trabalho permanece acentuada assimetria de saberes/poderes entre as categorias profissionais, entre estes e suas chefias e entre todos esses e os usuários. Para sua superação, portanto, não basta a qualificação técnica e para o agir individualizado; há que afirmar autonomias em interdependência ${ }^{27}$ ou um equilíbrio entre autonomia individual e coletiva ${ }^{21}$, daí exigindo-se cada vez mais uma formação que se abra para o trabalho em equipe, a se corresponsabilizar no enfrentamento dessas tendências. Um novo modelo de cuidado exige das práticas educativas o compromisso ético-político de produzir alterações no mundo do trabalho e na própria formação, com base nas necessidades reais.

\section{Avaliação e transversalidade}

A avaliação será explorada nos tópicos seguintes, compreendendo sua função estratégica na operacionalização da formação-intervenção, trazendo o trabalho ao centro das análises. Diz-se de uma inserção como nexo da prática pedagógica (constituinte dela), ao invés da posição usual de anexo dos projetos; nexo no sentido de articular os elementos do processo/prática formativa9 . Operada como um acompanhamento avaliativo, institui-se valorizando o caráter formativo, inclusivo e emancipatório da avaliação, advindo das abordagens participativas e construtivistas ${ }^{28}$. A ênfase recai sobre o modo de fazer, com aportes que ampliam o agir avaliativo, potencializando técnicas, estratégias e participação dos sujeitos. Por modo de fazer afirma-se um caminho promotor de inclusão, valorizando os pontos de vista dos múltiplos sujeitos, associando a inclusão a uma qualidade diferenciada de participação, na condição de coautoria de todo o processo avaliativo ${ }^{29}$.

Nos cursos em pauta, os envolvidos têm diferentes tipos de inserções no mundo do trabalho, falando do lugar de trabalhadores-alunos, professores, preceptores, tutores, profissionais dos serviços, gestores, etc. É desses lugares que ficam convocados à coautoria nos processos avaliativos, construindo os rumos analíticos de movimentos e de transformações perspectivados na caminhada formativa. Trata-se de rumos para superar a tradição de práticas avaliativas supostamente neutras, externas (anexas), com focos de interesse (im)postos por um ator-pesquisador externo e descomprometido com as transformações desejadas no processo. É um movimento de inclusão em que todos são remetidos à condição de investigadores-pesquisadores. E tem caráter (trans)formador pelas interferências no próprio processo, correções de rumo e alterações nas subjetividades dos envolvidos. Retomando a concepção de trabalho na relação entre o prescrito e o real, a avaliação está presente neste entre, isto é, comparecendo entre a norma e a renormatizaçã $0^{30}$; avaliação como nexo.

\section{Metodologia}

\section{Componentes articulados no caminho metodológico}

Essa proposta metodológica foi desenvolvida tendo por campo cursos multicêntricos de especialização em enfermagem obstétrica coordenados pela UFMG entre 2016 e 2018, abrangendo: 20 cursos descentralizados nos estados, 1.150 profissionais (alunos, professores, coordenadores, tutores, preceptores, monitores), 400 serviços de saúde (campos de estágio e hospitais de atuação dos alunos).

Nos itens seguintes destacam-se os focos articulados no caminho metodológico, passando por estratégias, técnicas e instrumentos avaliativos, com conceitos que sustentam o caminho nos moldes de pesquisa-intervenção. Demarcados os focos, segue-se com as dimensões de análise que acompanham as experiências.

\section{Acompanhamento avaliativo como função corresponsabilizada}

Operada como uma estratégia e uma lógica estruturante dos cursos, a avaliação não fica a cargo de uma pessoa/especialista, mas de todos os sujei- 
tos envolvidos e como fio condutor nos projetos. É posta a se fazer transversalmente. Conta-se com apoiadores do campo do planejamento e avaliação, como referência teórico-metodológica, mas tendo esse próprio apoio a função de oferta de um novo modo de fazer avaliação. A articulação de apoio e formação não remete a um olhar avaliativo especializado externo, em paralelo, mas de uma inclusão (na equipe e na estratégia de condução dos cursos) de um olhar compartilhado e produtor de conhecimento junto com o próprio grupo. Apoio que dá suporte às análises coletivas do trabalho e ajudando que os cursos configurem-se como processo formativo para toda a equipe e promovendo a coautoria no processo avaliativo. Um dos sentidos pedagógicos é o de se criar uma cultura avaliativa corresponsabilizada, superando a tradição de práticas punitivas, fiscalizatórias e excludentes.

Nos cursos, pela larga abrangência territorial, e com autonomia das instituições colaboradoras, deu-se ênfase a pactuações em oficinas iniciais de alinhamentos com as coordenações, seguindo-se em agendas locais inseridas no percurso.

\section{Acompanhamento avaliativo para interconectar planejamento, desenvolvimento e monitoramento e articular processos-efeitos}

$\mathrm{Na}$ transversalidade do acompanhamento avaliativo Planejamento, Monitoramento e Avaliação (PMA) são propostos como indissociáveis, integrados na estruturação de planos (das atividades do curso, de ação nos serviços, etc.), análises e apoio à implementação dos planos. A função integradora da avaliação permite costurar os elementos distribuídos no planejamento e desenvolvimento das atividades (trabalho pedagógico). Tem foco direcionado no que e no como se delineia o processo formativo e seguindo no que/ como se apreende ou se cria, se compartilha, se alcança, em termos de movimentos e efeitos de subjetivação ${ }^{16}$, isto é, na esfera das coisas que se produzem, das práticas, etc. e na emancipação e autonomia dos sujeitos em formação. A integração de PMA é também um caminho para envolver o profissional no aprendizado do agir inseparável de planejar-implementar-avaliar, colocando-o na condição de estudioso-aprendiz permanente de seu trabalho, o que aumenta a potência de nele interferir. Instrumentos estratégicos (diagnóstico-avaliativos e de planejamento) ajudam no agenciamento dessa função protagonista ou num ergoengajamento, como entende Schwartz ${ }^{30}$.
O desenho dos cursos deixa ver o modo transversal de articulação do $P M A$, numa engrenagem de coletivos (de equipes condutoras no nível central e descentralizadas nas escolas/estados/serviços) em fluxos de interações (formulações de projetos, ações, estratégias, planos e seus ajustamentos), funcionando com mútuas intervenções e todos os espaços e processos compreendidos como espaços avaliativo-formativos. Vale ressaltar o desafio da disposição das próprias instituições de ensino e professores para formarem-se simultaneamente em vários âmbitos de aprendizagens.

\section{Acompanhamento avaliativo entre a norma e a renormatização}

O acompanhamento avaliativo tem como um dos pontos de partida as normas para os processos de formação, compreendendo-se como normas (prescrito) os princípios-metas de desenvolvimento dos cursos. Mas a perspectiva avaliativa serve a ajustamentos, portanto não se tratando de uma simples verificação, ex-post, de cumprimento de normas, mas de um deslocamento do foco para a problematização/ajuste contínuo da experiência. Reafirma-se que a ênfase recai sobre o modo de fazer, inclusive do exercício avaliativo, referindo-se a modos cogeridos, participativos e corresponsáveis de discutir e conduzir processos (na saúde/educação e na avaliação). A atividade avaliativa desloca-se para um lugar especial de estar entre a norma e as renormatizações necessárias, na função de ajuste ao real.

\section{Acompanhamento avaliativo como prática de análise-intervenção}

Primeiro de tudo evoca-se a noção de intervenção que realça um pressuposto essencial da avaliação, que é seu compromisso com a transformação de realidades. $\mathrm{Na}$ análise institucional ${ }^{14}$ intervenção está sempre associada a ações e dispositivos que promovam alterações nos processos instituídos, isto é, potentes para produzir subjetivações associadas a mudanças. Uma prática avaliativa só se justifica com a disponibilidade para operar mudança. Esse alinhamento abre caminho para várias aproximações úteis ao campo avaliativo nos cursos e direciona os focos operacionais continuados a seguir.

\section{Análise coletiva do trabalho}

Segundo $\mathrm{Clot}^{25}$, realiza-se análise para aumentar o poder de agir dos coletivos sobre o am- 
biente de trabalho e sobre si mesmos, com a finalidade de compreender para transformar. Nessa direção o processo avaliativo passa pela análise coletiva do trabalho, aqui realçada na função de desvelar as relações que os sujeitos estabelecem com o trabalho, que mobilizam seus desejos e interesses e incidem na construção de autonomia e corresponsabilização com inovações e transformação da realidade. Ao se envolver na coprodução das análises, com o desvelamento de suas realidades, avança-se em agenciamentos de (novos) sujeitos, elementos e recursos para ampliar interpretações e enfrentamento de situações.

Ao se provocar essas análises no trabalho obstetriconeonatal, possibilita-se vir à tona os múltiplos sujeitos de interesse e múltiplos valores que o perpassam. Por aí desvelam-se não somente lacunas de qualificação (e de necessidades) para a prática, mas, de modo indissociado, os fatores da organização do trabalho, que explicam as conhecidas dificuldades de inserção dos enfermeiros e seu protagonismo no trabalho em equipe.

\section{Indicadores como analisadores do trabalho}

Os analisadores institucionais ${ }^{14}$ são propostos para superar ou dialogar com o conceito clássico de indicadores, estes nem sempre capazes de refletir realidades complexas e às vezes dela descontextualizados. Trata-se de elementos que revelam as singularidades institucionais, mostram o que fica escondido, os poderes e as forças presentes nos modos aparentemente neutros de organização e relações de trabalho. A avaliação produzida com e pelos analisadores produz desestabilizações e mudanças na ordem vigente e no próprio processo avaliativo. Nesse rumo, em seu modo de fazer, a avaliação provoca os sujeitos a se capacitar/formar, levantar, construir, inventar e pactuar situações, metas e indicadores-analisadores que orientem a renovação do trabalho ${ }^{29,31}$.

Nos cursos em questão, as oficinas de análise coletiva são momentos potentes para a produção de analisadores da organização do trabalho. Os frequentes relatos de estarem fora da assistência ou nela subutilizados, ou desqualificados pelos outros, geram oportunidade de se analisarem os fatores envolvidos nessa condição de marginalidade, fazendo emergir os elementos presentes na lógica instituída do trabalho e na aceitação dessa condição/submissão, mesmo se tendo formação, preparo técnico e legitimidade para o exercício profissional. São elementos que dizem do trabalho e subjetivações em seu contexto, dimensões abarcadas numa avaliação comprometida com mudanças. É esse movimento que subsidia deslocamentos e aumenta o poder de agir. Assim se podem ver os enfermeiros, no decorrer dos cursos, crescendo em sua capacidade de melhor analisar sua posição nos espaços de trabalho, passo essencial para reposicionamentos diante de si e das situações.

\section{Acompanhamento avaliativo e cartografia de processos-efeitos}

Ao enfatizar um modo de fazer está-se principalmente dizendo do tipo de movimentação estabelecida no caminho. Acentua-se o caráter cartográfico do acompanhamento avaliativo. Para Rolnik $^{17}$ a cartografia é um desenho que acompanha e se faz ao mesmo tempo em que ocorrem os movimentos de transformação da paisagem. $\mathrm{Na}$ movimentação dos cursos muito importam essas direções cartográficas alinhadas à ideia de avaliação como nexo, isto é, costurando os elementos do processo formativo e produzindo ação-conhecimento de como o processo se institui e suas repercussões. Mais do que isso, conhecendoconstruindo o próprio objeto em questão. Sobre este objeto cursos, por exemplo, pode-se afirmar que não seria possível conhecer-construindo-os por avaliações tradicionais, mas só pela via do acompanhamento avaliativo, na caminhada com eles, ajudando-os a se constituir e eles ajudando a avaliação a se fazer.

Os cursos geram uma produção incessante de movimentos, numa lógica efetivamente rizomática ${ }^{17}$, em fluxos que passam por múltiplos territórios (os serviços de saúde e as escolas, mas também os conselhos e entidades de classe, organizações sociais, de gênero, igreja, família, amigos, comunidade, ministério público, etc). São uma produção ampliada de redes, impossível ser conhecida não fosse pela abertura cartográfica. Esses fluxos são visibilizados por meio das vivências singulares, em ato, nos diferentes espaços e também pela produção de narrativas que se espalham em formas de comunicação em rede. Abrangem-se movimentos diversos que extrapolam a sala de aula. Englobam múltiplas situações em que os enfermeiros passam a realizar um procedimento (de assumir a assistência a um parto, de protagonismo em uma admissão/internação de gestante, de decidir sobre a indicação de uma determinada prática, de estar em determinados espaços antes proibidos, etc), como situações que exigiram enfrentamento da ordem instituída em um local, refletindo portanto deslocamentos dos sujeitos em formação nos contextos de trabalho. 
Abrangem protagonismo pela busca das entidades de classe para potencializar uma intervenção em um serviço ou do ministério público para ajudar em uma determinada situação. Tais movimentos são entendidos como efeitos-processo ou produtos-processo dos cursos e a função mais útil do acompanhamento avaliativo consiste em ajudar a fazer emergir tais ações-processos-efeitos.

\section{Instrumentos avaliativos como dispositivos de formação}

Nessas propostas formativas dois instrumentos cumprem especial função de convergir o seu desenvolvimento e a avaliação: diagnóstico situacional e planos de intervenção. Eles são a principal estratégia para trazer o trabalho ao centro da cena. São estratégicos em vários sentidos, como disparadores de olhar avaliativo sobre o próprio trabalho e como meio de os trabalhadores-alunos acionarem todos os envolvidos (professores, preceptores, tutores, equipes dos serviços) para a discussão do trabalho. São dispositivos especiais porque evitam que se fique no aprendizado de conteúdos abstratos ou descontextualizados. São disparadores de análises coletivas e põem os trabalhadores como pesquisadores de seu próprio ofício. E, ainda, funcionam como dispositivos estratégicos não pela descrição da realidade, mas porque se instituem despertando o olhar para realidades possíveis de serem (trans)formadas. Permitem ao trabalhador-aluno experienciar (e trazer à tona) suas afetações a partir/com aqueles cenários. Servem a um avaliador-cartógrafo a exercitar a atenção avaliativa não voltada para uma simples coleta e seleção de informações na realidade, mas atenção flutuante e aberta aos elementos de surpresa do processo e aos sinais "que indicam que algo acontece"25.

Também merece destaque outro importante instrumento mediador da experiência: os diários de campo. Potencializado como dispositivo ${ }^{31}$, permite restituir, na linguagem, a experiência vivida, como produção de conhecimento sobre o processo, ao mesmo tempo sendo um guia de ajustes em seu percurso. Não se trata apenas de um registro informativo das ações, de dados de observação, etc. É o registro do vivido, escapando de valorizar somente os resultados finais.

\section{Dimensões analíticas no acompanhamento avaliativo}

Ao problematizar o trabalho e sua finalidade como produção de serviço, Zarifian ${ }^{22,23}$ o postula como necessária interação de recursos e pessoas, aprendendo com o próprio fazer e gerando resultados considerados válidos, úteis, pelas pessoas (usuários e profissionais). Aqui ressalta-se o desafio essencial do serviço cursos, o de fortalecimento do protagonismo e autonomia para contribuir com mudanças de modelo de trabalho/ cuidado. Nessa direção, a avaliação nos cursos e sua utilidade como produção de serviço passa pelo cruzamento de vários elementos nas dimensões articuladas no Quadro 1. A transversalização das dimensões amplia a perspectiva investigativa, associada a aprendizagens interligando esferas organizacionais (do curso e dos serviços de saúde) e as subjetividades dos trabalhadores. Aqui não se trata de pensar competências/habilidades (dos trabalhadores) e mudanças de processos organizacionais num plano idealizado e abstrato, mas, como já dito, avaliação posta no entre as normas e renormatizações, focando-se no que se aprende-implementa com as situações vividas; o que emerge como tomadas de iniciativa e assunção de (co)responsabilidade na atividade situada o que os coletivos de trabalhadores aprendem e põem em funcionamento para dar conta do trabalho e do cuidado.

Diversas situações podem ilustrar essa produção de serviço na formação para atenção ao parto e nascimento. A formação-cuidado que se efetiva no seio dos serviços e na relação equipe-usuários expressa-se na capacidade dos cursos de produzir interferências nos processos de trabalho, na adoção de boas práticas, em novos modos de integração ensino-serviço, na tessitura de redes e nos modos de interações e vínculos que vão além de assistência em sentido restrito e fazem diferença nas vidas dos sujeitos envolvidos, usuários (gestantes) e trabalhadores, num momento tão singular de encontro desses sujeitos. Por esse contexto, alerta-se para a necessária ampliação do olhar avaliativo em diferentes âmbitos de processos e efeitos e superando o enfoque centrado em produtividade, em desempenho do aluno-trabalhador e outros indicadores restritos de eficiência, eficácia e efetividade. Trata-se de ampliar indicadores-analisadores afinados com ganho de autonomia, protagonismo e novos modos de gerir e de cuidar.

O horizonte alargado de utilidade (do trabalho e da avaliação) é então canalizado em três dimensões num enfoque transversal-transdimensional, no Quadro 1: pela dimensão I, focam-se as bases do processo de formação, colocando-o em análise para ajustes e validações de seus eixos de planejamento/ação pedagógica; pela di- 
Quadro 1. Acompanhamento avaliativo transversal de processos de formação-intervenção.

\begin{tabular}{|c|c|c|}
\hline $\begin{array}{l}\text { Objeto/Dimensão de } \\
\text { análise I }\end{array}$ & Objeto/Dimensão de análise II & $\begin{array}{c}\text { Objeto/Dimensão de } \\
\text { análise III }\end{array}$ \\
\hline $\begin{array}{l}\text { O Curso e sua dinâmica: } \\
\text { estrutura, conteúdos } \\
\text { e estratégias político- } \\
\text { pedagogicometodológicas }\end{array}$ & $\begin{array}{l}\text { Os sujeitos-equipes e sua dinâmica: os sujeitos no } \\
\text { contexto do processo de trabalho e da formação (e } \\
\text { as relações aí estabelecidas) }\end{array}$ & $\begin{array}{l}\text { O serviço e sua dinâmica: } \\
\text { as repercussões da formação } \\
\text { para a dinâmica dos } \\
\text { serviços e suas práticas de } \\
\text { gestão, cuidado e formação }\end{array}$ \\
\hline \multicolumn{3}{|c|}{ Dimensões/Focos de análise: processos e efeitos } \\
\hline $\begin{array}{l}\text { Abrange o } \\
\text { acompanhamento- } \\
\text { investigação do } \\
\text { planejamento e ajustes ou } \\
\text { regulações em seu próprio } \\
\text { desenho e implementação; } \\
\text { diz da organização, } \\
\text { arranjos, articulação das } \\
\text { práticas pedagógicas, } \\
\text { recursos } \\
\text { (Aspectos que informam } \\
\text { sobre a capacidade do } \\
\text { projeto de funcionar como } \\
\text { intervenção) }\end{array}$ & $\begin{array}{l}\text { Aspectos que informam sobre as habilidades } \\
\text { técnicas e sobre a inserção-inclusão dos } \\
\text { trabalhadores nos processos de trabalho e de } \\
\text { formação e a produção de intersubjetividade } \\
\text { (considerando as modalidades de trabalho } \\
\text { induzidas pelos serviços e pelos cursos). Também } \\
\text { a articulação/produção de práticas de integração } \\
\text { (trabalho-formação) } \\
\text { Autonomia, Protagonismo } \\
\text { (como sujeitos, equipes) } \\
\text { Pode-se ilustrar com os seguintes focos de } \\
\text { avaliação: . Oportunidade de articulação de } \\
\text { saberes, do 'conhecimento prático', dos objetos, } \\
\text { dos processos, práticas e relações de trabalho (em } \\
\text { equipe) } \\
\text {. articulação/produção de práticas coletivas, } \\
\text { integradas entre os profissionais } \\
\text {. articulação/produção de estratégias de renovação } \\
\text { de sua atuação, do funcionamento como equipe, } \\
\text { na relação entre pares e com a hierarquia de gestão } \\
\text {. articulação de interesses para construção/ } \\
\text { invenção de projetos comuns e construção de redes }\end{array}$ & $\begin{array}{l}\text { Repercussões nos processos } \\
\text { de trabalho e tipos de } \\
\text { práticas de atenção, gestão e } \\
\text { formação incorporados na } \\
\text { dinâmica dos serviços e na } \\
\text { relação com os usuários. }\end{array}$ \\
\hline
\end{tabular}

Fonte: Santos Filho $(2010 ; 2014)^{9,13}$

mensão II, analisa-se seu alcance na formação dos trabalhadores/alunos, compreendidos como sujeitos no contexto do processo de trabalho e da formação; e pela dimensão III, a repercussão na organização dos serviços e cuidado aos usuários. Abrem-se para explorar a capacidade do curso, como intervenção, de gerar efeitos em diferentes e indissociáveis sentidos: mudanças nos processos, nas práticas sanitárias, nos sujeitos e relações. Nessa linha o acompanhamento avaliativo se faz criando espaços de análise tomando como indissociáveis os planos de produção dos serviços e dos sujeitos. É um movimento que, como já dito, possibilita que sujeito, objeto e estratégias criemse ao mesmo tempo.

\section{Conclusão: práticas produtoras de redes}

Os objetivos da formação-intervenção convergem para a ampliação de redes em diferentes rumos: redes de sujeitos com maior capacidade de intervir nos modos de gerir e de cuidar, por articular o trabalho em equipe e interequipes, interconectar atividades, produtos, saberes, ações, serviços, estes e as escolas (em novos modos de integração ensino-serviço) e também conexão com as entidades do entorno.

Possibilita-se que os profissionais de EO reconheçam-se como atores estratégicos para a mudança do modelo ainda vigente, induzindo-se que o sistema e seus atores, em construção conjunta das políticas públicas (de saúde e formação), pactuem a efetiva atuação integrada. E que, por meio de novas interações em equipe, com gestantes, famílias e sociedade, possa-se avançar em uma formação multiprofissional comprometida com ressignificações e renovação dos sentidos de parir, nascer e viver, prezando as evidências científicas, mas contribuindo na desmedicalização da atenção. 
O acompanhamento avaliativo e métodos integrando a formação permitem acompanhar-investigar a realidade, tecendo e desvelando as redes que a constituem e potencializando sua perspectiva rizomática. Trata-se, portanto, de métodos/ práticas geradoras de rede, ressaltando a compreensão de rede como arranjos físicos, técnicos, políticos e afetivos, ou arranjos de cuidado em sentido ampliado, aí subjazendo linhas de força para sustentar grupalidades, movimentos de afetações e de corresponsabilização.

Vale reforçar a estreita interlocução dessa proposta metodológica com campos teórico-políticos de especial importância na discussão da saúde no Brasil. Nesse rumo, articula-se no campo da educação permanente nos horizontes em que os autores brasileiros a abordam no SUS ${ }^{20,27}$; conecta-se com o campo da humanização na acepção ético-estético-política trazida em seu marco conceitual e em suas experimentações no SUS ${ }^{9,10,13,19,32}$; alinha-se à concepção de cogestão em saúde como método para articular e formar equipes para o trabalho ${ }^{33}$; e se insere em linhagens avaliativas construtivistas ${ }^{28}$ que inspiram pesquisadores e trabalhadores em diferentes experiências no SUS. Também, no campo mais específico da atenção ao parto/nascimento e âmbito da enfermagem obstétrica, a proposta traz o potencial de responder aos desafios metodológicos (antigos e recorrentes) que se impõem aos processos formativos comprometidos com a transformação do modelo de atenção vigente $\mathrm{e}^{3,5,6,34}$.

Nessas direções, os processos formativo e avaliativo se fazem em conexão com a produção de redes e tal produção se faz principalmente escutando diferentes pontos de vista no caminho, efetivandose em uma espiral de negociação entre sujeitos. Por isso, trata-se de um processo de contratualização instituinte na organização, desestabilizando objetos instituídos, reconhecendo e redistribuindo funções, saberes e poderes, e os coletivos assumindo a coautoria do processo avaliativo ${ }^{29}$.

Uma importante direção do acompanhamento avaliativo é o seu alinhamento à premissa de que toda experiência pedagógica traga em si uma perspectiva investigativa, de indagação permanente. Como diz Paulo Freire ${ }^{35}$, são indicotomizáveis os atos de formar e de pesquisar. Nesses sentidos reforça-se a perspectiva de indissociar formação e avaliação-pesquisa-intervenção sobre a própria prática pedagógica. A utilidade desse modo de fazer avaliação não recai somente em aprendizagens e ajustamentos no processo, mas também porque subsidia ou coincide com a produção de uma metodologia tanto de formação quanto de avaliação. Esses cursos/experiências se propõem como práticas de formação e pesquisa avaliativa (ergo)engajada, esperando-se apropriação dos processos e efeitos pelos coletivos, convergindo na coprodução de conhecimento-ação.

Como projetos interinstitucionais e no compromisso de transformações na realidade, os cursos na ótica da formação-intervenção em EO devem ser alvo de avaliações capazes de indicar seu potencial e de contribuir tanto na sua implementação quanto na produção/legitimação de conhecimento sobre a ação pedagógica e sobre avaliação. Evidentemente essa prática traz desafios, num exercício criterioso, exigindo análises de implicações ${ }^{14}$ e multiplicando espaços avaliativo-formativo-participativos a colocar em análise a própria avaliação, reconhecendo suas limitações. Para o enriquecimento dessas experiências, outras perspectivas avaliativas devem ser abertas, lembrando a inquestionável pertinência da pluralidade de abordagens.

\section{Colaboradores}

SB Santos Filho: concepção do projeto, análise, redação e revisão crítica. KV Souza: concepção do projeto, análise e revisão crítica. 


\section{Referências}

1. Organização Pan-Americana da Saúde (OPAS). Centro Latino-Americano de Perinatologia, Saúde da Mulher e Reprodutiva. Conjunto de ferramentas para o fortalecimento da parteira nas Américas. Montevidéu: CLAP/SMR; 2014.

2. Comissão Nacional de Incorporação de Tecnologias no SUS (CONITEC). Relatório de Recomendação. Diretriz Nacional de Assistência ao Parto Normal. Brasília: MS; 2016.

3. Costa AANM, Schirmer J. A atuação dos enfermeiros egressos do curso de especialização em obstetrícia no nordeste do Brasil - da proposta à operacionalização. Esc Anna Nery 2012; 16(2):332-339.

4. Leal MC, Gama SGN. Nascer no Brasil. Cad Saude Publica 2014; 30(Supl. 1):S5.

5. Amorim T, Gualda DMR. Coadjuvantes das mudanças no contexto do ensino e da prática da enfermagem obstétrica. Rev Rene 2011; 12(4):833-840.

6. Pereira ALF, Nicácio MC. Formação e inserção profissional das egressas do curso de residência em enfermagem obstétrica. Rev Enferm UERJ 2014; 22(1):5056.

7. Barros MEB, Barros RB. A potência formativa do trabalho em equipe no campo da saúde. In: Pinheiro $\mathrm{R}$, Mattos RA, Barros MEB, organizadores Trabalho em equipe sob o eixo da integralidade: valores, saberes $e$ práticas. Rio de Janeiro: IMS/UERJ, CEPESC, ABRASCO; 2007. p. 75-84.

8. Heckert AL, Neves CAB. Modos de formar e modos de intervir: quando a formação se faz potência de produção de coletivo. In: Brasil. Ministério da Saúde (MS). Formação e intervenção. Brasília: MS; 2010. p. 13-27. (Série B. Textos Básicos de Saúde).

9. Santos Filho SB. Avaliação e Humanização em Saúde: aproximações metodológicas. Ijuí: Unijuí; 2010.

10. Brasil. Ministério da Saúde (MS). Formação e intervenção. Brasília: MS; 2010. (Série B. Textos Básicos de Saúde).

11. Guattari F. Psicanálise e transversalidade. Aparecida, SP: Ideias e Letras; 2004.

12. Passos E, Barros RB. A cartografia como método de pesquisa-intervenção. In: Passos E, Kastrup V, Escóssia L, organizadores. Pistas do método da cartografia: pesquisa-intervenção e produção de subjetividade. Porto Alegre: Sulina; 2010. p. 17-31.

13. Santos Filho SB. Pesquisa em humanização: articulações metodológicas com o campo da avaliação. Saude Transform Soc 2014; 5(2):1-10.

14. Lourau R. A análise institucional. Petrópolis: Vozes; 1995.

15. Deleuze G, Guattari F. Mil platôs. São Paulo: Ed 34; 1995.

16. Baremblitt GF. O inconsciente institucional. Belo Horizonte: FGC/IFG; 2011.

17. Rolnik S. Cartografia sentimental. Porto Alegre: Sulina/UFRS; 2006.

18. Kastrup V. O funcionamento da atenção no trabalho do cartógrafo. In: Passos E, Kastrup V, Escóssia L. Pistas do método da cartografia: pesquisa-intervenção $e$ produção de subjetividade. Porto Alegre: Sulina; 2010. p. $32-51$.
19. Brasil. Ministério da Saúde (MS). HumanizaSUS: documento base para gestores e trabalhadores do SUS. Brasília: MS; 2008.

20. Ceccim RB. Conexões e fronteiras da interprofissionalidade: forma e formação. Interface (Botucatu) 2018; 22(Supl. 2):1739-1749.

21. Dejours C. O fator humano. Rio de Janeiro: FGV; 1997.

22. Zarifian P. Mutação dos sistemas produtivos e competências profissionais: a produção industrial de serviço. In: Salerno MS, organizador. Relação de serviço: produção e avaliação. São Paulo: Senac; 2001. p. 67-94.

23. Zarifian P. Valor, organização e competência na produção de serviço: esboço de um modelo de produção de serviço. In: Salerno MS, organizador. Relação de serviço: produção e avaliação. São Paulo: Senac; 2001. p. 95-149.

24. Schwartz Y, Durrive L. Trabalho e ergologia: conversas sobre a atividade humana. Niterói: EdUFF; 2007.

25. Clot Y. Trabalho e poder de agir. Belo Horizonte: Fabrefactum; 2010.

26. Gomes RM. Humanização e desumanização no trabatho em saúde. Rio de Janeiro: Fiocruz; 2017.

27. Peduzzi M. Equipe multiprofissional de saúde: conceito e tipologia. Rev Saude Publica 2001; 35(1):103109.

28. Guba EG, Lincoln YS. Avaliação de quarta geração. Campinas: Editora da Unicamp; 2011.

29. Santos Filho SB, Souza TP, Gonçalves L. Avaliação como dispositivo de humanização em saúde: considerações metodológicas. In: Onocko Campos R, Furtado JP. Desafios da avaliação de programas e serviços em saúde: novas tendências e questões emergentes. Campinas: Ed. Unicamp; 2011. p. 257-278.

30. Schwartz Y. Manifesto por um ergoengajamento. In: Bendassolli PF, Soboll LA. Clínicas do trabalho: novas perspectivas para a compreensão do trabalho na atualidade. São Paulo: Atlas; 2011. p. 132-166.

31. Santos Filho SB. Perspectivas da Avaliação na Política Nacional de Humanização: aspectos conceituais e metodológicos. Cien Saude Colet 2007; 12(4):999-1010.

32. Benevides R, Passos E. A humanização como dimensão pública das políticas de saúde. Cien Saude Colet 2005; 10(3):315-325.

33. Campos GWS, Cunha GT, Figueiredo MD. Práxis e formação Paideia: apoio e cogestão em saúde. São Paulo: Hucitec; 2013.

34. Gama SG, Viellas EF, Torres JA, Bastos MH, Brüggemann OM, Theme Filha MM, Schilithz AO, Leal MD. Labor and birth care by nurse with midwifery skills in Brazil. Reprod Health 2016; 13(Supl. 3):123.

35. Freire P. Pedagogia da autonomia: saberes necessários à prática educativa. São Paulo: Paz e Terra; 1996.

Artigo apresentado em 22/02/2019

Aprovado em 20/08/2019

Versão final apresentada em 30/09/2019 